\title{
Higher mortality rate is associated with advanced age and periodic lateralized epileptiform discharges in patients with refractory status epilepticus
}

\author{
Alta taxa de mortalidade está associada com idade avançada e descargas periódicas \\ lateralizadas em pacientes com estado de mal epiléptico refratário
}

Paulo Breno Noronha Liberalesso, Eliana Garzon, Elza M.T. Yacubian, Américo C. Sakamoto

\begin{abstract}
Objective: To evaluate clinical data, electroencephalogram, etiology, classification, treatment, morbidity, and mortality in acute refractory status epilepticus. Methods: Fifteen patients, mean age of 41.3 years-old, six males, with refractory status epilepticus, were retrospectively studied. All of them were followed by serial electroencephalogram or continuous electroencephalographic monitoring. Results: The most common comorbidity was hypertension. Seven (46.7\%) patients were diagnosed with previous symptomatic focal epilepsy. More than one etiology was identified in $40.0 \%$ of the cases. Status epilepticus partial complex was the most common ( $n=14$, 93.3\%), and discrete seizures were the most observed initial ictal pattern. Continuous intravenous midazolam was used in nine (60.0\%) patients and continuous thiopental in three (20.0\%). Nine (60.0\%) participants died, one (6.6\%) had neurological sequelae, and five (33.3\%) presented no neurological sequelae. Conclusions: Higher mortality rate was associated with advanced age and periodic lateralized epileptiform discharges. Midazolam proved to be a safe drug. The refractory status epilepticus is related to high mortality.
\end{abstract}

Key words: status epilepticus, treatment, prognosis, age.

\section{RESUMO}

Objetivo: Avaliar os dados clínicos, o eletroencefalograma, a etiologia, a classificação, o tratamento, a morbidade e a mortalidade do estado de mal epiléptico. Métodos: Quinze pacientes, idade média de 41,3 anos, seis masculinos, foram avaliados retrospectivamente. Todos eles foram acompanhados por eletroencefalogramas seriados ou monitoração eletrencefalográfica contínua. Resultados: A comorbidade mais comum foi hipertensão arterial. Sete (46,7\%) pacientes tinham epilepsia focal sintomática prévia. Mais de uma etiologia foi identificada em $40,0 \%$ dos casos. 0 estado de mal epiléptico parcial complexo foi o mais frequente $(n=14 ; 93,3 \%)$ e discrete seizures foram os padrões ictal inicial mais observados. Midazolam contínuo foi usado em nove (60,0\%) pacientes e tiopental contínuo em três (20,0\%). Nove (60,0\%) participantes morreram, um (6,6\%) teve sequelas neurológicas e cinco $(33,3 \%)$ não apresentaram sequelas. Conclusões: Alta taxa de mortalidade foi associada com idade avançada e com a presença de descargas periódicas epileptiformes lateralizadas. Midazolam provou ser uma droga segura. Estado de mal epiléptico refratário está associado à alta mortalidade.

Palavras-Chave: estado de mal epiléptico, tratamento, prognóstico, idade.

Status epilepticus (SE) is considered the main emergency in clinical neurology, requiring immediate diagnosis and treatment. Recent data suggest an incidence from 100,000 to 200,000 cases, per year ${ }^{1}$.

The SE definitions proposed by the Committee of Classification and Terminology of the International League Against Epilepsy (ILAE - 1964 and 1981) ${ }^{2,3}$ do not consider the event duration factor. Therefore, different investigators have used different definitions, impairing the uniformity of the concept. Many authors consider SE a single epileptic seizure or two or more recurrent epileptic seizures without full recovery of consciousness, lasting 30 minutes or more ${ }^{4}$. This definition has been widely used over the last 20 years, although several authors have suggested that such concept should include epileptic seizure lasting more than five or ten minutes ${ }^{5,6}$. However, the increase in mortality and in

MD, PhD, Hospital São Paulo, Escola Paulista de Medicina, Federal University of São Paulo, São Paulo SP, Brazil.

Correspondence: Paulo Breno Noronha Liberalesso; Rua Benjamin Constant 90, apto. 73; 80060-020 Curitiba PR - Brasil; E-mail: paulo.neuroped@gmail.com Conflict of interest: There is no conflict of interest to declare.

Received 29 September 2012; Accepted 05 October 2012. 
a definitive neurological lesion related to epileptic seizures with more than 30 minutes appears to justify the maintenance of the current definition.

Epidemiological data regarding morbidity and mortality vary considerably and are closely related to patient's age, etiology and duration of the seizures, early diagnosis, and therapeutic conduct adopted ${ }^{7,8}$. Studies on animal models have suggested that continuous and prolonged epileptiform activity per se may be related to irreversible neuronal damage 9 .

The most serious form of SE is denoted refractory SE (RSE), which is understood as SE that cannot be clinically and/or electrographically controlled with first and second line antiepileptic drugs (AED) ${ }^{10}$. Other authors consider SE to be refractory after failure of treatment with a third line AED ${ }^{11}$. Some of them reserve the term RSE for epileptic seizure, with more than one hour ${ }^{12,13}$, while others reserve the term for seizures lasting more than two hours ${ }^{14}$.

Clinical practice demonstrates that a considerable proportion of patients with SE develop refractoriness to clinical treatment, although few studies are available with specific emphasis on the epidemiological aspects of RSE.

In the present study, we analyzed patients with RSE diagnosis in order to identify the etiology of the condition, to evaluate its clinical and electrographic evolution, the treatment, the complications during the acute phase, and the possible risk factors that contributed to mortality.

\section{METHODS}

All patients with RSE diagnosis admitted between January 2001 and September 2004 were retrospectively identified. All medical records were reviewed by the same investigator, who also filled out all previously elaborated protocols. All participants were submitted to continuous electroencephalographic monitoring or to serial electroencephalographies (EEGs) lasting at least 20 minutes by using 21-channel digital equipment (Nihon Koden ${ }^{\circledR}$ and NEUROTEC ${ }^{\circledR}$ ), with the electrodes positioned according to the 10-20 International System. We evaluated demographic data; medical history, etiology and clinical classification of SE; electrographic patterns; use of first, second, and third line AED; treatment during RSE; and short-term prognosis.

For SE classification, we used the classification of epileptic seizures and SE of Gastaut ${ }^{4}$ : generalized convulsive SE (tonic-clonic, tonic, clonic, myoclonic); simple partial convulsive SE; nonconvulsive generalized SE; complex partial nonconvulsive SE; and simple partial nonconvulsive SE.

The following definitions were adopted:

- SE: a single epileptic seizure or two or more recurrent ones without recovery of consciousness and lasting 30 minutes or more.
- RSE: SE for which no clinical and/or electrographic control of the epileptic phenomenon was obtained after intravenous administration of appropriate doses of first and second line AED, such as benzodiazepines, phenytoin, and phenobarbital.

- Ictal patterns: five distinct patterns were considered discrete seizures (DS) merging seizures (MS), continuous ictal discharge (CID), CID with flat periods (CID-F), and periodic lateralized epileptic discharges (PLEDs).

- Control of SE: control was defined as the last clinical and/or electrographic seizure after which the patient did not suffer recurrence of an epileptic seizure for at least 48 hours.

- Failure of RSE treatment: permanence or recurrence within less than 48 hours after clinical and electrographic controls and the maximum tolerated dose of continuously infused midazolam, thiopental, or propofol.

- Minimum tolerated dose: continuously infused dose of midazolam, thiopental or propofol related to the onset of severe side effects, which prevented the maintenance of the drug.

- Short-term prognosis: neurological status evaluated during the first two weeks after RSE control.

The study was approved by the Hospital Ethics and Human Research Committee (1312/02).

\section{RESULTS}

We clinically and electrographically evaluated 15 patients with a RSE diagnosis, six (40.0\%) of them males, ranging in age from 1 to 84 years-old (mean: 41.3 years-old; median: 50 years-old), six by continuous electroencephalographic monitoring, and nine by serial EEGs (43 serial recordings). Fourteen patients presented comorbidities, the most prevalent being systemic arterial hypertension $(n=6$; $40.0 \%)$, chronic congestive heart failure $(n=3 ; 20.0 \%)$, diabetes mellitus ( $n=3 ; 20.0 \%)$, chronic renal failure $(n=2 ; 13.3 \%)$, and ischemic cerebrovascular accident $(n=2 ; 13.3 \%)$. Seven patients $(46.7 \%)$ had a previous diagnosis of symptomatic focal epilepsy (Table 1).

It was possible to identify the etiology of RSE in all cases, with more than one etiology being detected in six (40.0\%) patients. Fourteen $(93.3 \%)$ cases were classified as complex partial SE and one (6.7\%) as myoclonic SE. The most frequent initial ictal pattern was DS ( $n=6 ; 40 \%)$, with more than one ictal pattern being recorded in eight (53.3\%) cases during the course of RSE. PLEDs occurred in three (20.0\%) cases as the initial ictal pattern and during the course of RSE in one $(6.7 \%)$ of them (Table 1).

Diazepam was used as the most frequent first line $\operatorname{AED}(n=6 ; 40.0 \%)$, phenytoin as the second $(n=8 ; 53.3 \%)$, 
Table 1. Demographic data, base diseases, epilepsy, classification of status epilepticus, and ictal patterns.

\begin{tabular}{|c|c|c|c|c|c|c|c|}
\hline Patient & Sex & Age & Base diseases & Epilepsy & Etiology & Classification & Ictal patterns \\
\hline 1 & $\mathrm{~F}$ & 53 & $\begin{array}{l}\text { SAH, neurocysticercosis, } \\
\text { chronic gastritis }\end{array}$ & Yes & $\begin{array}{c}\text { Neurocysticercosis, intracranial } \\
\text { hypertension }\end{array}$ & Complex partial & $\begin{array}{l}\text { PLEDs, CID, } \\
\text { CID-F, DS }\end{array}$ \\
\hline 2 & $\mathrm{~F}$ & 50 & Glioblastoma & Yes & Sepsis & Complex partial & DS, MS \\
\hline 3 & M & 59 & $\begin{array}{c}\text { SAH } \\
\text { Chronic renal failure }\end{array}$ & No & Metabolic disorder, sepsis & Complex partial & CID \\
\hline 4 & $\mathrm{~F}$ & 84 & $\begin{array}{l}\text { SAH, Parkinson's disease, } \\
\text { chronic heart failure }\end{array}$ & No & Traumatic brain injury & Complex partial & PLEDs, MS \\
\hline 5 & M & 81 & $\begin{array}{l}\text { SAH, DM, rectal neoplasia, } \\
\text { chronic heart failure }\end{array}$ & No & Cardiorespiratory arrest & Myoclonic & $\mathrm{CID}-\mathrm{F}$ \\
\hline 6 & M & 26 & Aids & No & $\begin{array}{c}\text { Structural brain lesion, } \\
\text { meningitis }\end{array}$ & Complex partial & PLEDs \\
\hline 7 & M & 21 & $\begin{array}{l}\text { Live cirrhosis; chronic renal } \\
\text { failure }\end{array}$ & No & Metabolic disorder, sepsis & Complex partial & MS \\
\hline 8 & $\mathrm{~F}$ & 69 & SAH, CVAI & Yes & Sepsis & Complex partial & CID-F, PLEDs \\
\hline 9 & $\mathrm{~F}$ & 3 & Mucopolysaccharidosis & Yes & Cardiorespiratory arrest & Complex partial & MS, CID, CID-F \\
\hline 10 & $\mathrm{~F}$ & 84 & $\begin{array}{c}\text { SAH, DM } \\
\text { Chronic heart failure }\end{array}$ & No & CVAl & Complex partial & CID \\
\hline 11 & M & 50 & DM, CVAl & Yes & Metabolic disorder, sepsis & Complex partial & DS \\
\hline 12 & $\mathrm{~F}$ & 7 & $\begin{array}{l}\text { Rhinopharynx } \\
\text { rhabdomyosarcoma }\end{array}$ & No & Brain metastasis & Complex partial & DS \\
\hline 13 & $\mathrm{~F}$ & 1 & --- & Yes & $\begin{array}{c}\text { Pneumonia, respiratory } \\
\text { insufficiency }\end{array}$ & Complex partial & DS, MS, CID \\
\hline 14 & $\mathrm{~F}$ & 23 & --- & No & Postvaccinal encephalitis & Complex partial & DS, MS \\
\hline 15 & M & 9 & Postencephalitis sequel & Yes & $\begin{array}{c}\text { Decompensation of } \\
\text { symptomatic focal epilepsy }\end{array}$ & Complex partial & DS, MS \\
\hline
\end{tabular}

F: female; M: male; SAH: systemic arterial hypertension; DM: diabetes mellitus: Aids: acquired immunodeficiency syndrome; CVAl: ischemic cerebrovascular accident; PLEDs: periodic lateralized epileptiform discharges; CID: continuous ictal discharges; CID-F: continuous ictal discharges with flat periods; MS: merging seizures; DS: discrete seizures.

and phenobarbital as the third ( $\mathrm{n}=7 ; 46.7 \%)$. After RSE diagnosis, continuous intravenous infusion of midazolam was used for nine $(60.0 \%)$ patients, followed by continuous thiopental in three cases. In six $(40.0 \%)$ patients, after the detection of RSE, the option was treatment by polytherapy without infusion of midazolam and/or thiopental (Table 2).

In the group of patients treated with continuous midazolam $(n=7)$, the mean attack dose was $10.5 \mathrm{mg}$, and the mean maximum dose reached was $0.42 \mathrm{mg} / \mathrm{kg} / \mathrm{h}$, with a mean use time of 4.2 days. During continuous midazolam infusion, an adverse effect of the drug was observed in three (20.0\%) patients (arterial hypotension), with the administration of dopamine being necessary in two cases (Table 2).

Three patients were treated with continuous thiopental infusion, with a mean maximum dose reached of $3.9 \mathrm{mg} / \mathrm{kg} / \mathrm{h}$ and a mean time of use of 3.5 days. The three patients presented arterial hypotension during infusion of the drug, with the administration of dopamine being necessary in two cases and discontinuation of the drug being required in only one.

Regarding the short-term course, nine $(60.0 \%)$ patients died, five $(33.3 \%)$ had no neurological sequels, and one $(6.6 \%)$ had neurological sequels. In six $(40.0 \%)$ patients, it was possible to obtain control of RSE within a mean time of 33.6 hours.

\section{DISCUSSION}

RSE physiopathology has peculiarities related to its duration and severity, with emphasis on hypoglycemia secondary to excessive insulin release, faulty self-regulation of cerebral blood flow, excitotoxic neuronal damage, brain edema, increased body temperature related to muscle activity, and during a later phase multiple organ and system dysfunction followed by cardiovascular failure ${ }^{11,15}$. RSE has peculiar characteristics compared to SE, with a higher risk of complications and morbidity and mortality.

\section{Age and sex}

Although practically half the cases of SE affect children and adolescents, several studies have demonstrated that individuals above the age of 60 years represent a population at risk $^{15,16}$. In general, SE seems to present a bimodal age distribution, with a first incidence peak among children younger than 12 months and another among elderly patients ${ }^{2}$. In the present series, most of the patients were adults (73.3\%). Approximately two thirds of the patients were older than 50 years-old and one third was older than 80 , suggesting that increasing age is accompanied by an increasing risk of refractoriness in cases of SE.

Regarding distribution by gender, literature data are conflicting, some studies demonstrate a predominance of SE 
Table 2. Patients treated with continuous midazolam and short-term evolution of refractory status epilepticus.

\begin{tabular}{|c|c|c|c|c|c|c|c|c|}
\hline Patient & Age & $\begin{array}{l}\text { Attack dose } \\
\text { (MDZ) }\end{array}$ & $\begin{array}{l}\text { Maximum dose } \\
\text { (MDZ) }\end{array}$ & $\begin{array}{l}\text { Time of use } \\
\text { (MDZ) }\end{array}$ & $\begin{array}{l}\text { Adverse effects } \\
\text { (MDZ) }\end{array}$ & $\begin{array}{l}\text { Treatment of } \\
\text { RSE }\end{array}$ & $\begin{array}{l}\text { Ictal } \\
\text { patterns }\end{array}$ & $\begin{array}{c}\text { RSE } \\
\text { outcome }\end{array}$ \\
\hline 1 & 53 & $15 \mathrm{mg}$ & 0.45 & 5 days & No & MDZ,THP & $\begin{array}{c}\text { PLEDs, CID, CID-F, } \\
\text { DS }\end{array}$ & Death \\
\hline 2 & 50 & $15 \mathrm{mg}$ & 0.40 & 4 days & No & MDZ & DS, MS & Death \\
\hline 3 & 59 & $10 \mathrm{mg}$ & 0.25 & 6 days & No & MDZ & CID & Death \\
\hline 4 & 84 & $15 \mathrm{mg}$ & 0.35 & 6 days & No & MDZ & PLEDs, MS & Death \\
\hline 5 & 81 & $10 \mathrm{mg}$ & 0.25 & 3 days & $\begin{array}{l}\text { Systemic arterial } \\
\text { hypotension }\end{array}$ & MDZ & CID-F & Death \\
\hline 6 & 26 & $10 \mathrm{mg}$ & 0.40 & 3 days & No & MDZ,THP & PLEDs & Death \\
\hline 7 & 21 & - & - & - & - & PB, PHT & MS & Control \\
\hline 8 & 69 & - & - & - & - & PB, PHT & CID-F, PLEDs & Control \\
\hline 9 & 3 & $4.5 \mathrm{mg}$ & 0.65 & 6 days & No & MDZ & MS, CID, CID-F & Control \\
\hline 10 & 84 & - & - & - & - & $\mathrm{PB}, \mathrm{PHT}$ & CID & Death \\
\hline 11 & 50 & - & - & - & - & PB, PHT & DS & Death \\
\hline 12 & 7 & - & - & - & - & PB, PHT & DS & Control \\
\hline 13 & 1 & - & - & - & - & PB, PHT, TPM & DS, MS, CID & Control \\
\hline 14 & 23 & $10 \mathrm{mg}$ & 0.8 & 2 days & $\begin{array}{l}\text { Systemic arterial } \\
\text { hypotension }\end{array}$ & $\begin{array}{l}\text { MDZ,THP } \\
\text { Propofol }\end{array}$ & DS, MS & Death \\
\hline 15 & 9 & $5,0 \mathrm{mg}$ & 0.2 & 3 days & $\begin{array}{l}\text { Systemic arterial } \\
\text { hypotension }\end{array}$ & $\begin{array}{c}\text { VPA, PB, PHT, } \\
\text { MDZ }\end{array}$ & DS, MS & Control \\
\hline
\end{tabular}

MDZ: midazolam; Maximum dose in mg/kg/day; THP: thiopental; PB: phenobarbital; PHT: phenytoin; TPM: topiramate; VPA: sodium valproate; RSE: refractory status epilepticus; PLEDs: periodic lateralized epileptiform discharges; CID: continuous ictal discharges; CID-F: continuous ictal discharges with flat periods; MS: merging seizures; DS: discrete seizures.

among males ${ }^{16}$, while others show predominance among females $^{17}$. In the present study we observed a predominance among females $(\mathrm{n}=9 ; 60.0 \%)$

\section{Comorbidities and etiology}

Approximately one third of SE cases are deemed idiopathic, occurring in neurologically healthy individuals and representing the first manifestation of an epileptic picture ${ }^{18,19}$.

Age and presence of previous unprovoked epileptic seizures are important aspects for the evaluation of SE etiology. Among children and small infants, febrile/infectious situations, anoxic lesions, traumatic brain injury, meningoencephalitis and chronic nonprogressive encephalopathy are responsible for a considerable portion of SE cases ${ }^{19,20}$; whereas among adults and elderly individuals, cerebrovascular disorders metabolic disorders and infection of the central nervous system are the most frequent ${ }^{16,17,21,22}$. Among previously epileptic patients, changes in the treatment scheme or irregular use of AED is the factor triggering $\mathrm{SE}$ in most situations ${ }^{22}$. In a large study involving more than 200 patients, Barry and Hauser ${ }^{23}$ suggested that a meticulous investigation of SE etiology should be performed even in previously epileptic patients, since half of these patients have a base disease or an acute brain injury as the factor triggering the current SE.

The etiology was classified as acute symptomatic in $14(93.3 \%)$ of our patients. SE was due to decompensation of previous symptomatic focal epilepsy in only one of our cases. Sepsis and metabolic disorders were conspicuous for their high frequency. In contrast to the literature, the etiology related to cerebral ischemia was infrequent in our series, with only one case secondary to an ischemic cerebrovascular accident and two secondary to cardiorespiratory arrest being observed.

Probably due to the predominance of elderly patients in our study, comorbidities were present in most cases $(n=13$; 86.7\%), with emphasis on systemic arterial hypertension, diabetes mellitus, and chronic congestive heart failure. The presence of comorbidities/base diseases among elderly patients may impair the etiologic identification of SE.

A previous history of symptomatic focal epilepsy was observed in practically half of our patients ( $n=7 ; 46.7 \%)$, although decompensation of previous refractory epilepsy was implicated as the etiology in only one case.

\section{Classification of refractory status epilepticus}

According to Gastaut ${ }^{4}$, SE can be classified as generalized convulsive (tonic-clonic, tonic, clonic, myoclonic); simple partial convulsive (somatomotor, postural motor, continuous partial epilepsy); generalized nonconvulsive (typical and atypical absence); simple partial nonconvulsive (somatosensory, sensory, autonomic, psychic or affective, motor inhibitory), and complex partial nonconvulsive. Except for one of our patients diagnosed as having myoclonic RSE, all others presented complex partial RSE. These data agree with the current literature, which indicates that complex partial SE is the most frequent condition in critically ill adult and elderly patients ${ }^{8}$.

Several studies have demonstrated that clinical evaluation may be insufficient for the diagnosis and classification 
of SE, with serial or continuous electroencephalographic recordings being required. According to DeLorenzo ${ }^{24}$, about $8 \%$ of comatose patients with no motor manifestation suggestive of epileptic seizures are in nonconvulsive SE, and this diagnosis can be confirmed exclusively by the EEG. The permanence of continuous epileptiform activity over a prolonged period is positively related to increased mortality and neurological morbidity, and diagnosis and treatment should be established as early as possible ${ }^{25}$. In our series, two patients were unconscious and did not show any motor manifestation that might suggest the presence of epileptic seizures, revealing the importance of the EEG for the investigation of patients in a comatose state.

\section{Ictal patterns}

Treiman et al. ${ }^{26}$ suggested the existence of five ictal patterns that represent the natural history of the electrographic course of SE: DS with interictal slowing (this ictal pattern was observed as the initial ictal pattern in six cases and during the course of RSE in one case); MS (this ictal pattern was observed in two cases as the initial ictal pattern and in five cases during the course of RSE); continuous ictal discharges (this ictal pattern was observed in the initial recording in two of our cases and during the course of SE in three other cases); continuous ictal discharges with flat periods (this pattern was initially observed in two cases and during the course of SE in two other patients); and PLEDs (this pattern was observed in the initial recording in three patients and during the course of RSE in only one case).

PLEDs represent an electrographic finding of particularly difficult interpretation, with many investigators considering them an unequivocal ictal pattern ${ }^{27}$, although they may be observed in situations not related to SE.

In contrast to the results reported by Treiman et al. ${ }^{26}$ regarding patients with generalized convulsive SE, our data did not confirm the presence of a stereotyped sequence of ictal patterns during the course of complex partial SE.

\section{Treatment}

The objective of treating patients with SE is clinical and electrographic controls within the shortest possible time, since there is evidence suggesting that a longer duration of SE is accompanied by an increased refractoriness to treatment.

Although SE diagnosis is based on at least 30 minutes of continuous ictal activity, this theoretical definition has no implications regarding the decision about the beginning of clinical treatment. Although there are variations in protocols, most authors consider benzodiazepines, phenytoin, and phenobarbital the AED of choice for the initial management of these patients. In a study in which $111 \mathrm{SE}$ episodes were evaluated clinically and electrographically in 102 patients, SE could not be controlled with first or second line AED in $11.7 \%$ of cases, which corresponded to RSE. Benzodiazepines are potent AED that should be used only in the presence of epileptic seizures, always accompanied by another AED of longer-lasting action such as the phenytoin. Intravenous formulations of diazepam and lorazepam (the latter not available in Brazil) are the first line drugs most commonly used, because of their rapid initiation of action due to their high liposolubility 28,29 .

Phenobarbital has been used in many cases as a second line drug in the treatment of SE, especially in newborn and young infants. Shaner et al. ${ }^{29}$ compared the efficacy of phenobarbital and diazepam in combination with phenytoin for the initial treatment of SE, but they observed no significant differences between treatments.

Patients with nonconvulsive SE, particularly those with a history of epilepsy, should not be treated in an aggressive manner such as by induction of barbituric coma, which increases the risk of neurological morbidity and mortality, offsetting the benefits of early control of SE.

In the present study, the first line AED most frequently used for the treatment of SE was diazepam, the second line drug was phenytoin and the third one was phenobarbital. Once RSE was observed, continuous infusion of midazolam was the therapeutic conduct in most cases, with systemic arterial hypotension being detected as a side effect in three patients and easily controlled with dopamine. The three patients treated with thiopental developed severe systemic arterial hypotension, which required discontinuation of the drug in one case and treatment with dopamine in the other two.

\section{Short-term prognosis}

Several series have demonstrated that the prognosis of patients with SE is closely related to etiology and that both mortality and risk of neurological sequels are more frequent among adults/elderly subjects than among children ${ }^{30}$.

The morbidity-mortality rate varies considerably in different studies depending on factors such as patient age, presence of base diseases and clinical complications, classification of SE, and the therapeutic conduct adopted. Maytal et al..$^{30}$, studying aspects related to prognosis in 193 children and adolescents who had presented SE, observed a $3.6 \%$ mortality rate during the first three months and a $9.1 \%$ of neurological sequels. These values were significantly lower than those detected by other investigators in a series of adults/elderly subjects with SE, in which mortality ranged from 9.3 to $88.0 \%^{16,17}$.

Other factors in addition to advanced age seem to be associated with poorer prognosis, such as the presence of cerebral anoxia, low voltage cerebral electrical activity and PLEDs in the EEG, lack of response to first and second line AED (RSE), lasting of more than one hour, and combination of more than one etiological factor. Mortality, neurological morbidity, and risk of later epilepsy are significantly higher 
in RSE than in nonrefractory $\mathrm{SE}^{22}$. On the other hand, cases related to discontinuation or alteration of AED among previously epileptic patients and those related to alcoholism have lower morbidity-mortality. Other aspects such as sex and race do not seem to affect the prognosis of $\mathrm{SE}^{22}$.

Regarding the short-term prognosis, the present data agree with those reported in the literature, with more than half of our patients ( $n=9 ; 60 \%)$ dying, and approximately one quarter showing no additional neurological sequels during the first two weeks after controlling RSE.

In conclusion, in the present series we observed a predominance of RSE in adults/elderly individuals, with two thirds of our patients being over the age of 50 . All patients older than more 80 years-old and more than half of the ones older than 50 years-old died, confirming the high mortality rate occurring in elderly individuals.

All patients who presented PLEDs at some time during the course of RSE died, confirming previous literature reports that associate this ictal pattern with high mortality rate. The presence of previous symptomatic focal epilepsy did not affect the prognosis of RSE.

Treatment of RSE with continuous midazolam infusion proved to be safe, with side effects being observed and easily controlled in three cases. In contrast, the administration of thiopental was accompanied by severe hypotension, requiring discontinuation of the drug in one patient.

Despite adequate treatment, RSE is related to a high rate of neurological mortality and morbidity.

\section{References}

1. DeLorenzo RJ, Hauser WA, Towne AR, et al. A prospective populationbased epidemiologic study of status epilepticus in Richmond, Virginia. Neurology 1996;46:1029-1035

2. Commission on Classification and Terminology of the International League Against Epilepsy. A proposed international classification of epileptic seizures. Epilepsia 1964;5:297-306

3. Commission on Classification and Terminology of the International League Against Epilepsy. Proposal for revised clinical and electroencephalographic classification of epileptic seizures. Epilepsia 1981;22:489-501.

4. Gastaut H. Classification of status epilepticus. In: Delgado-Escueta AV, Wasterlain CG, Treiman DM, Porter RJ (ed). Status epilepticus. Mechanisms of brain damage and treatment. New York: Raven Press; 1983. pp. 15-35.

5. Lowenstein DH, Bleck T, Macdonal RL. It's time to revise the definition of status epilepticus. Epilepsia 1999;40:120-122.

6. Lowenstein DH, Alldredge BK. Status epilepticus. N Engl J Med 1998;338:970-976.

7. Aminoff MJ, Simon RP. Status epilepticus: causes, clinical features and consequences in 98 patients. Am J Med 1980;69:657-666.

8. DeLorenzo RJ, Towne AR, Pellock JM, Ko D. Status epilepticus in children, adults and the elderly. Epilepsia 1992;33(Suppl.4): S15-S25.

9. Meldrum BS, Brierley JB. Prolonged epileptic seizures in primates: ischemic cell change and its relationship to ictal physiological events. Arch Neurol 1973;28:10-17.

10. Jagoda A, Riggio S. Refractory status epilepticus in adults. Ann Emerg Med 1993;22:1337-1348.

11. Bleck TP. Advances in the management of refractory status epilepticus. Crit Care Med 1993;21:955-957.

12. Hanley DF, Kross JF. Use of midazolam in the treatment of refractory status epilepticus. Clin Ther 1998;20:1093-10105.

13. Mayer SA, Claassen J, Lokin J, Mendelsohn F, Dennis LJ, Fitzsimmons BF. Refractory status epilepticus. Frequency, risk factors, and impact on outcome. Arch Neurol 2002;59:205-210.

14. Prasad A, Worrall BB, Bertram EH, Bleck TP. Propofol and midazolam in the treatment of refractory status epilepticus. Epilepsia 2001;42:380-386.
15. Meldrum BS, Horton RW. Physiology of status epilepticus in primates. Arch Neurol 1973;28:1-9.

16. Knake S, Rosenow F, Vescovi M, et al. Incidence of status epilepticus in adults in Germany: A prospective, population-based study. Epilepsia 2001;42:714-8.

17. Vignatelli L, Tonon C, D’Alessandro R. Incidence and short-term prognosis of status epilepticus in adults in Bologna, Italy. Epilepsia 2003;44:964-968.

18. Aicardi J, Chevrie JJ. Convulsive status epilepticus in infants and children: a study of 239 cases. Epilepsia 1970;11:187-197.

19. Dunn DW. Status epilepticus in children: etiology, clinical features, and outcome.J Child Neurol 1988;3:167-173.

20. Oliveira D, Oliveira MJ, Alves V, Temudo T. Estado de mal epiléptico en niño. Revisión de siete años. Rev Neurol 2000;30:414-418.

21. Hauser WA, Anderson VE, Loewenson RB. Seizure recurrence after a first unprovoked seizure. N Engl J Med 1982;307:522-528.

22. Towne AR, Pellock JM, Ko D, DeLorenzo RJ. Determinants of mortality in status epilepticus. Epilepsia 1994;35:27-34.

23. Barry E, Hauser WA. Status epilepticus: the interaction of epilepsy and acute brain disease. Neurology 1993;43:1473-1478.

24. DeLorenzo RJ. Prevalence of nonconvulsive status epilepticus in comatose patients. Neurology 2000;54:340-350.

25. Lowenstein DH, Aminoff MJ. Clinical and EEG features of status epilepticus in comatose patients. Neurology 1992;42:100-104.

26. Treiman DM, Walton NY, Kendrick C. A progressive sequence of electroencephalographic changes during generalized convulsive status epilepticus. Epilepsy Res 1990;5:49-60.

27. Garzon E, Fernandes RMF, Sakamoto AC. Serial EEG during human status epilepticus. Evidence for PLED as an ictal pattern. Neurology 2001;57:1175-1183.

28. LeppikIE,DerivanAT,Homan RW, etal.Double-blind study of lorazepam and midazolam in status epilepticus. JAMA 1983;249:1452-1454.

29. Shaner DM, McCurdy SA, Herring MO, et al. Treatment of status epilepticus: a prospective comparison of diazepam and phenytoin versus phenobarbital and optional phenytoin. Neurology 1988;38:202-207.

30. Maytal J, Shinnar S, Moshé SL, Alvarez LA. Low morbidity and mortality of status epilepticus in children. Pedriatrics 1989;83:323-331. 